\title{
Angka Lempeng Total Mikroba pada Minuman Teh di Kota Pontianak
}

\author{
Gita Wiratna*, Rahmawati ${ }^{1}$, Riza Linda ${ }^{1}$ \\ ${ }^{1}$ Program Studi Biologi, Fakultas MIPA, Universitas Tanjungpura, JL. Prof. Dr. H. Hadari Nawawi, Pontianak \\ *Email korespondensi: gitawiratna789@gmail.com
}

\begin{abstract}
Tea drinks are presumed to be contaminated by microbes. The presence of microbes can be one of the biological parameters that can determine whether food and drinks are worth to consume. This study was conducted to determine the value of microbial Total Plate Count (TPC) in tea drink samples sold in Pontianak city. The samples were obtained in six locations which were one cafe and five traditional markets. Samples taken were ice cubes, tea with ice cubes, and tea without ice cubes. Samples test was done in duplicate and the result stated that the lowest TPC were found in tea with ice cubes samples $22,6 \times 10^{2} \mathrm{CFU} / \mathrm{ml}$, while the highest TPC were found in ice cubes samples is $32200 \times 10^{2} \mathrm{CFU} / \mathrm{ml}$.
\end{abstract}

Keywords: Ice cube, Microbes, Tea drinks, Total Plate Count (TPC)

\section{PENDAHULUAN}

Minuman teh merupakan salah satu minuman olahan yang berasal dari daun (pucuk) teh yang dikenal di Indonesia dan di Dunia. Minuman teh dapat dikonsumsi apabila bersih dan aman dari komponen-komponen berbahaya atau organisme yang dapat menyebabkan keracunan atau menimbulkan penyakit. Alwi dan Maulina (2012) menyatakan keberadaan mikroba dapat menjadi salah satu parameter biologis yang dapat menentukan layak atau tidaknya makanan dan minuman tersebut untuk dikonsumsi.

Pemeriksaan adanya mikroba dapat dilakukan menggunakan metode Angka Lempeng Total (ALT). Metode Angka Lempeng Total (ALT) merupakan metode kuantitatif untuk mengetahui jumlah mikroba yang ada pada suatu sampel. Menurut Rizal (2006) metode ALT merupakan metode perhitungan jumlah koloni mikroba aerob mesofilik. Metode ALT dapat digunakan dengan cara tuang, cara tetes, dan cara sebar.

Batas cemaran mikroba yang ditetapkan BPOM (2016) pada pemeriksaan ALT minuman teh maksimal $10^{2}$ koloni/ml. Sinabaria (2017) menemukan ALT pada teh kering dalam kemasan sebanyak $77 \times 10^{1} \mathrm{koloni} / \mathrm{ml}$. Hal ini menunjukkan belum banyak informasi mengenai penelitian tentang ALT pada minuman teh, salah satunya yang ada di Kota Pontianak. Mengingat rentan terjadinya kontaminasi pada minuman teh, maka perlu dilakukan pemeriksaan ALT mikroba pada minuman teh di Kota Pontianak.

\section{BAHAN DAN METODE}

Waktu dan Tempat Penelitian

Penelitian dilaksanakan pada bulan Agustus sampai Oktober 2018, penelitian ini dilakukan di Laboratorium Mikrobiologi, Jurusan Biologi, Fakultas Matematika dan Ilmu Pengetahuan Alam Universitas Tanjungpura Pontianak, Kalimantan Barat.

\footnotetext{
Alat dan Bahan

Alat yang digunakan dalam penelitian ini adalah autoklaf, Bunsen, cawan petri, colony counter, cool box, cool pack, Erlenmeyer, gelas beaker, hot plate, inkubator, jarum ose, kamera, kertas, klin pack, label, Biosafety Cabinet (BSC), mikro pipet, pipet ukur, plastik pembungkus, tabung reaksi, thermometer, termos es, timbangan analitik, vortex.

Bahan yang digunakan adalah akuades, alkohol, media Buffered Peptone Water (BPW), media Nutrient Agar (NA), media Plate Count Agar (PCA), sampel air teh tanpa menggunakan es batu, teh menggunakan es batu, dan es batu.

\section{Pengambilan Sampel}

Sampel dibeli dari beberapa pedagang es teh yang ada di Kota Pontianak secara acak pada enam pasar tradisional di Kota Pontianak, Sampel yang diambil meliputi minuman teh tanpa es batu, minuman teh menggunakan es batu, dan es batu, total jumlah sampel yang diambil adalah sebanyak 18 sampel. Sampel yang dibeli dari pedagang dimasukkan ke dalam plastik dan dimasukkan langsung ke dalam cool box yang telah diberi cool pack, lalu di bawa ke laboratorium dan langsung dilakukan analisis. Pada saat pengujian terlebih dahulu suhu sampel tersebut diukur mengunakan thermometer.
} 


\section{Cara Kerja}

Sampel diambil sebanyak $1 \mathrm{ml}$ dan dimasukkan ke dalam tabung reaksi yang berisi $9 \mathrm{ml}$ media BPW (suspensi), selanjutnya diambil $1 \mathrm{ml}$ larutan dan dimasukkan ke dalam tabung reaksi yang berisi $9 \mathrm{ml}$ media BPW $\left(10^{-1}\right)$ dihomogenkan, kemudian di ambil $1 \mathrm{ml}$ dan di masukkan ke dalam tabung reaksi yang berisi $9 \mathrm{ml}$ media BPW $\left(10^{-2}\right)$ dan diperlakukan dengan cara yang sama sampai pengenceran $10^{-4}$. Selanjutnya masing-masing pengenceran diambil sebanyak $1 \mathrm{ml}$ dan dimasukkan ke cawan petri yang telah berisi $15 \mathrm{ml}$ media PCA secara duplo, lalu dihomogenkan dan ditutup (Hartati, 2016), kemudian diinkubasi pada suhu $37^{\circ} \mathrm{C}$ selama 48 jam. Perhitungan yang dilakukan hanya untuk pengenceran dengan jumlah koloni 30-300.
Rumus ALT sebagai berikut (Thayib \& Amar, 1989):

$$
\text { Jumlah koloni setiap cawan } \times \frac{1}{\text { Faktor pengenceran }}
$$

\begin{abstract}
Analisis Data
Data hasil perhitungan nilai ALT mikroba dibandingkan dengan mengacu pada nilai standar yang telah ditetapkan oleh BPOM (2016) mengenai batas maksimum cemaran mikroba dalam minuman teh yaitu $10^{2} \mathrm{koloni} / \mathrm{ml}$.
\end{abstract}

\section{HASIL DAN PEMBAHASAN}

\section{Hasil}

Berdasarkan hasil uji Angka Lemeng Total (ALT) pada 18 sampel, dimana 15 sampel diambil di pasar tradisional di Kota Pontianak dan 3 lainnya merupakan sampel pembanding disalah satu kafe di Kota Pontianak.

Tabel 1. Hasil Perhitungan Angka Lempeng Total (ALT) Minuman teh di Kota Pontianak

\begin{tabular}{ccccc}
\hline No & Lokasi & Es batu & Teh menggunakan es batu & Teh tanpa menggunakan es batu \\
\hline 1 & Kafe & $39 \times 10^{2}$ & $272 \times 10^{2}$ & $8400 \times 10^{2}$ \\
2 & PT I & $164 \times 10^{2}$ & $19400 \times 10^{2}$ & $29800 \times 10^{2}$ \\
3 & PT II & $32200 \times 10^{2}$ & $2190 \times 10^{2}$ & $1590 \times 10^{2}$ \\
4 & PT III & $11700 \times 10^{2}$ & $1160 \times 10^{2}$ & $11700 \times 10^{2}$ \\
5 & PT IV & $4900 \times 10^{2}$ & $193 \times 10^{2}$ & $300 \times 10^{2}$ \\
6 & PT V & $212 \times 10^{2}$ & $22.6 \times 10^{2}$ & $610 \times 10^{2}$ \\
\hline
\end{tabular}

Keterangan: $\mathrm{PT}=$ Pasar Tradisional

Hasil pengujian ALT mikroba menunjukkan bahwa semua sampel tidak memenuhi syarat. Hasil yang didapatkan melebihi batas maksimum cemaran mikroba menurut BPOM nomor 16 tahun 2016 yaitu $10^{2}$ koloni $/ \mathrm{ml}$.

Tabel 2. Hasil pengukuran suhu minuman teh pada saat pengujian

\begin{tabular}{cccc}
\hline \multicolumn{3}{c}{ Suhu Minuman $\left({ }^{\circ} \mathrm{C}\right)$} \\
\hline Lokasi & $\begin{array}{c}\text { Es } \\
\text { batu }\end{array}$ & $\begin{array}{c}\text { Teh } \\
\text { menggunakan } \\
\text { es batu }\end{array}$ & $\begin{array}{c}\text { Teh tanpa } \\
\text { menggunakan es } \\
\text { batu }\end{array}$ \\
\hline Kafe & 5 & 5 & 8 \\
PT I & 5 & 9 & 16 \\
PT II & 7 & 16 & 25 \\
PT III & 5 & 13 & 27 \\
PT IV & 7 & 10 & 17 \\
PT V & 6 & 9 & 16 \\
\hline
\end{tabular}

Keterangan: PT=Pasar Tradisional
Berdasarkan pengukuran suhu yang telah dilakukan diketahui suhu sampel berkisar antara

$5-27^{\circ} \mathrm{C}$. Suhu tertinggi pada sampel sampel teh yang tidak menggunakan es batu yaitu $27^{\circ} \mathrm{C}$ sedangkan suhu terendah yaitu $5^{\circ} \mathrm{C}$ yang terdapat pada sampel yang terdapat di Kafe (pembanding) yaitu teh yang menggunakan es batu, dan es batu. Sedangkan suhu $5^{\circ} \mathrm{C}$ juga didapatkan pada sampel es batu (Tabel 2).

Observasi faktor kebersihan dilakukan terhadap 6 pedagang minuman teh di Kota Pontianak. Faktor kebersihan yang diamati berupa kebersihan penjual serta peralatan yang digunakan. Hasil menyatakan bahwa semua pedagang tidak memenuhi kriteria persyaratan kebersihan oleh Kepmenkes RI Nomor (Kepmenkes RI Nomor: 942/Menkes/SK/VII/ 2003) (Tabel 3). 
Tabel 3. Tabel persyaratan kebersihan

\begin{tabular}{|c|c|c|c|c|c|c|c|}
\hline \multirow{2}{*}{\multicolumn{2}{|c|}{$\begin{array}{l}\text { Persyaratan Kebersihan Minuman (Kepmenkes RI } \\
\text { Nomor:942/Menkes/SK/VII/2003) }\end{array}$}} & \multicolumn{6}{|c|}{$\begin{array}{l}\text { Pelaksanaan di Pasar tradisional Kecamatan } \\
\text { Pontianak }\end{array}$} \\
\hline & & Kafe & PT I & PT II & PT III & PT IV & PT V \\
\hline \multicolumn{8}{|c|}{ Penjual Minuman ES } \\
\hline 1 & Memakai sarung tangan & $\mathrm{T}$ & $\mathrm{T}$ & $\mathrm{T}$ & $\mathrm{T}$ & $\mathrm{T}$ & $\mathrm{T}$ \\
\hline 2 & Memakai tutup kepala & $\mathrm{T}$ & $\mathrm{T}$ & $\mathrm{Y}$ & $\mathrm{T}$ & $\mathrm{Y}$ & $\mathrm{T}$ \\
\hline 3 & Memakai celemek & $\mathrm{T}$ & $\mathrm{T}$ & $\mathrm{T}$ & $\mathrm{T}$ & $\mathrm{T}$ & $\mathrm{T}$ \\
\hline 4 & Memakai masker & $\mathrm{T}$ & $\mathrm{T}$ & $\mathrm{T}$ & $\mathrm{T}$ & $\mathrm{T}$ & $\mathrm{T}$ \\
\hline 5 & Mencuci tangan setiap kali membuat minuman & $\mathrm{Y}$ & $\mathrm{T}$ & $\mathrm{T}$ & $\mathrm{T}$ & $\mathrm{T}$ & $\mathrm{T}$ \\
\hline \multicolumn{8}{|c|}{ Peralatan } \\
\hline 1 & Mencuci peralatan setiap kali digunakan & $\mathrm{Y}$ & $\mathrm{T}$ & $\mathrm{T}$ & $\mathrm{T}$ & $\mathrm{T}$ & $\mathrm{T}$ \\
\hline \multicolumn{8}{|c|}{ Bahan dan Pengelolaan } \\
\hline 1 & Minuman teh baru dibuat pada saat pemesanan & $\mathrm{T}$ & $\mathrm{T}$ & $\mathrm{T}$ & $\mathrm{T}$ & $\mathrm{Y}$ & $\mathrm{T}$ \\
\hline & $\begin{array}{l}\text { Air yang digunakan untuk pembuatan teh dimasak terlebih } \\
\text { dahulu }\end{array}$ & Y & Y & Y & Y & Y & Y \\
\hline 3 & $\begin{array}{l}\text { Air yang digunakan untuk pembuatan es batu dimasak } \\
\text { terlebih dahulu }\end{array}$ & $\mathrm{T}$ & $\mathrm{T}$ & $\mathrm{T}$ & $\mathrm{T}$ & $\mathrm{T}$ & $\mathrm{T}$ \\
\hline & $\begin{array}{l}\text { Air yang digunakan dalam pembuatan teh berupa air galon } \\
\text { atau PDAM }\end{array}$ & Y & Y & Y & Y & $\mathrm{Y}$ & Y \\
\hline & $\begin{array}{l}\text { Air yang digunakan dalam pembuatan es batu berupa air } \\
\text { galon, air PDAM, air hujan }\end{array}$ & Y & Y & Y & $\mathrm{Y}$ & Y & Y \\
\hline
\end{tabular}

Keterangan: $\mathrm{Y}=\mathrm{ya}, \mathrm{T}=$ tidak, $-=$ tidak diketahui, $\mathrm{PT}=$ Pasar Tradisional

\section{Pembahasan}

Penghitungan koloni bakteri dilakukan dengan menghitung semua koloni yang tumbuh pada permukaan media agar yang digunakan. Berdasarkan hasil menunjukkan bahwa nilai ALT tertinggi terdapat pada sampel es batu dari pasar tradisional II yaitu $32200 \times 10^{2} \mathrm{koloni} / \mathrm{ml}$, sedangkan yang terendah terdapat pada sampel pembanding (kafe) yaitu $39 \times 10^{2}$ koloni $/ \mathrm{ml}$. Sampel teh menggunakan es batu memiliki nilai ALT tertinggi terdapat pada pasar tradisional I yaitu $19400 \times 10^{2}$ koloni $/ \mathrm{ml}$, sedangkan yang terendah $22.6 \times 10^{2}$ koloni/ml di pasar tradisional $\mathrm{V}$, sedangkan untuk nilai ALT tertinggi terdapat pada sampel teh tanpa menggunakan es batu yaitu dari pasar tradisional II $29800 \times 10^{2} \mathrm{koloni} / \mathrm{ml}$, dan yang terendah terdapat di pasar tradisional IV yaitu $300 \times 10^{2} \mathrm{koloni} / \mathrm{ml}$ (Tabel 1). Hal ini menunjukkan bahwa semua sampel melebihi batas maksimum ALT yang telah ditetapkan oleh BPOM (2016) yaitu $10^{2} \mathrm{koloni} / \mathrm{ml}$.

Air merupakan salah satu bahan baku dalam pembuatan teh yang dapat menjadi sumber kontaminasi mikroba. Berdasarkan hasil observasi pada saat pengambilan sampel menunjukkan air dalam pembuatan teh dimasak terlebih dahulu, namun hasil menunjukkan masih terdapat mikroba pada sampel tersebut, hal ini diduga ada beberapa mikroba yang tahan pada suhu tinggi, yaitu bakteri golongan termofilik. Irdawati dan Fifendy (2011) terdapat bakteri anggota genus Aeromonas, Pseudomonas dan Vibrio di sumber mata air panas di Songgoriti dengan suhu air $50^{\circ} \mathrm{C}$. Air yang tidak dimasak dapat menjadi sumber kontaminasi. Berdasarkan hasil observasi untuk pembuatan es batu, air yang digunakan oleh pedagang tidak dimasak terlebih dahulu. Air hujan yang tidak dimasak diduga dapat menjadi sumber kontaminasi mikroba.

Berdasarkan penelitian Sari et al. (2015), pengujian angka lempeng total menunjukkan terdapat mikroba pada sampel air hujan yang disebabkan oleh adanya sumber kontaminasi di antaranya berasal dari atap dan bak penampung. Penelitian Zdeb et al. (2016) menunjukkan bahwa air hujan menggandung bakteri anggota spesies Clostridium perfingens, E.coli dan Streptococcus facealis. Hal ini menunjukkan air hujan dari tempat penampungan dapat terkontaminasi oleh mikroba.

Berdasarkan pengukuran suhu terhadap sampel pada saat pengujian diketahui mikroba dapat tumbuh pada suhu $5-27^{\circ} \mathrm{C}$, hal ini menunjukkan bakteri yang tumbuh masuk kedalam kelompok psikrofil dan mesofil. Hal ini sesuai dengan pernyataan Cappuucino dan Sherman (2014) yang menyatakan bahwa semua bakteri berdasarkan suhu pertumbuhannya dapat diklasifikasikan dalam tiga kelompok yaitu psikrofil dengan kisaran suhu pertumbuhan $\left(-5-20^{\circ} \mathrm{C}\right)$, mesofil $\left(10-45^{\circ} \mathrm{C}\right)$ dan termofil pada suhu diatas $45^{\circ} \mathrm{C}$. 
Selain air hujan, air galon juga dapat terkontaminasi oleh mikroba. Berdasarkan hasil observasi, pedagang minuman teh menggunakan air galon dalam pembuatan teh. Pada saat pengujian minuman teh, semua sampel mengandung mikroba, hal ini sesuai dengan penelitian Watung et al. (2014) yang menyatakan angka lempeng total pada depot air minum isi ulang berkisar antara 800$980000 \mathrm{koloni} / \mathrm{ml}$. Hal ini diperkuat oleh penelitian Rumondor et al. (2014) yang menunjukkan terdapat 33 bakteri yang terdapat pada air minum isi ulang di Kota Manado. Keberadaan mikroba pada air galon dapat disebabkan kurang bersihnya air galon, peralatan yang tidak bersih dan penjamah yang tidak higienis.

Keberadaan mikroba pada suatu sampel dapat menunjukkan adanya cemaran dalam suatu produk. Kontaminasi diduga dapat disebabkan oleh kurang bersihnya tempat pembuatan dan penjualan, kontaminasi mikroba juga dapat disebabkan oleh lama waktu penyimpanan. Ismail (2012) menyatakan kualitas kebersihan, kesehatan makanan dan minuman dapat mempengaruhi adanya kontaminasi mikroba. Berdasarkan hasil pengamatan semua pedagang minuman teh tidak melakukan praktek higiene pada saat pembuatan minuman teh sesuai dengan standar yang telah ditetapkan oleh Kepmenkes (2003) (Tabel 3).

Kontaminasi mikroba pada sampel erat kaitannya dengan faktor kebersihan, baik dari penjual, peralatan yang digunakan dan bahan-bahan yang digunakan. Aryani dan Anwar (2006) menyatakan praktek sanitasi dan higiene pedagang dapat menentukan tingkat pencemaran. Adanya mikroba pada setiap sampel yang diujikan menunjukkan adanya praktek sanitasi yang tidak baik, seperti halnya di pasar tradisional I, untuk persyaratan kebersihan minuman terutama penjual minumannya tidak mengikuti persyaratan yang telah ditentukan oleh Kepmenkes (2003), hal ini dapat dilihat diantaranya penjual tidak mneggunakan sarung tangan, tidak memakai penutup kepala, tidak memakai celemek, tidak memakai masker bahkan tidak mencuci tangan setiap kali membuat minuman (Tabel 3). Kondisi inilah yang diduga dapat menyebabkan adanya kontaminasi pada sampel yang diujikan. Bilqis et al. (2016) menyatakan penjamah merupakan sumber utama kontaminasi. Berdasarkan penelitian Fadhila et al. (2015) terdapat hubungan antara kondisi personal higiene penjamah dengan jumlah kuman yang terdapat pada makanan pedagang di Wilayah kampus UNDIP Tembalang.
Peralatan yang digunakan juga dapat berpotensi menyebabkan kontaminasi. Sulistiyani dan Zulaikah (2006) menyatakan penggunaan wadah yang tidak bersih dapat menjadi sumber kontaminasi mikroba. Berdasarkan hasil observasi mneunjukkan 5 dari 6 orang pada saat pengambilan sampel tidak mencuci peralatan yang digunakan, hal ini diduga dapat menyebabkan kontaminasi dari produk yang dihasilkan (Tabel 3). Penelitian Marisdayana et al. (2017) menunjukkan dari 11 pedagang yang menggunakan teknik pencucian yang kurang baik, semuanya memiliki jumlah koloni yang buruk, artinya jumlah koloni mikroba yang didapatkan melebihi batas maksimum keberadaan mikroba pada makanan.

\section{DAFTAR PUSTAKA}

Alwi, M \& Maulina, S, 2012, Pengujian Bakteri Coliform dan Escherichia coli pada Beberapa Depot Air Minum Isi Ulang di Kecamatan Palu Timur Kota Palu, Jurnal Biocelebes, vol. 6, no. 1, hal. 40-47.

Badan Pengawasan Obat dan Makanan RI (BPOM), 2016, Kriteria Mikrobiologi Dalam Pangan Olahan, BPOM RI, Jakarta.

Bilqis, RF, Wahyuningsih, NE \& Darundiati, YH, 2016, Faktor-Faktor Yang Berhubungan Dengan Jumlah Koloni Bakteri Dan Keberadaan E. coli Pada Air Cucian Peralatan Makan Pedagang Makanan Di Tembalang, Jurnal Kesehatan Masyarakat, vol. 4, no. 3, hal. 888-897.

Cappuccino, GJ \& Sherman, N, 2014, Manual Laboratorium Mikrobiologi, Edisi 8, Jakarta, EGC.

Fadhila, MF, Wahyuningsih, NE \& Hanani, YD, 2015, Hubungan Higiene Sanitasi Dengan Kualitas Bakteriologis Pada Alat Makan Pedagang Di Wilayah Sekitar Kampus UNDIP Tembalang, Jurnal Kesehatan Masyarakat, vol. 3, no. 4, hal. 769-776.

Hartati, FK, 2016, Evaluasi Pengujian Angka Lempeng Total Menggunakan Metode Petrifilm Aerobic Count Plate Terhadap Metode Uji SNI 01.2332.2006 pada Produk Perikanan di LPPMHP Surabaya, Jurnal Teknik Industri Heuristic, vol. 13, no. 2, hal. 89-105.

Irdawati \& Fifendy, M, 2011, Isolasi Bakteri Termofilik Penghasil Amilase dari Sumber Air Panas Rimbo Panti Pasaman, Fakultas MIPA, Jurusan Biologi,Universitas Negeri Padang. 
Ismail, D, 2012, Uji Bakteri Escherichia coli pada Minuman Susu Kedelai Bermerk dan Tanpa Merek di Kota Surakarta, Naskah Publikasi, Fakultas Kedokteran, Jurusan Pendidikan Dokter Universitas Muhammadiyah Surakarta.

Marisdayana, R, Sahara, PH \& Yosefin, H, 2017, Teknik Pencucian Alat Makanan Personal Hygiene Terhadap Kontaminasi Bakteri Pada Alat Makan, Jurnal Endurance, vol. 2, no. 3, hal. 376-382.

MenKes RI, 2003, KepMenkes RI No.942/MenKes/SK/VII/2003 Tentang Persyaratan Higiene Sanitasi Makanan Jajanan, DepKes RI, Jakarta.

Rizal, M, 2016, Analisis Kandungan MPN dan ALT pada Fish Nugget Berbahan Dasar Limbah Ikan, Jurnal Biologi Sel, vol. 5, no. 2, hal. 144-151.

Rumondor, PP, Porutu'o, J \& Waworuntu, O, 2014, Identifikasi Bakteri Pada Depot Air Minum Isi Ulang di Kota Manado, Jurnal e-Biomedik (Ebm), vol. 2, no. 2, hal. 1-4.

Sari, IP, Kurniawan, SV, Pudjilestari, L, \& Enty, 2015, Uji Bakteriologik Air Olahan Rain Water Harvesting System di SDN Pajagalan 01 dan 02 Jakarta Utara, Jurnal Of Medicine, vol. 14, no. 1, hal. 19-27.

Sinabariba, NMC, 2017, Uji Angaka Lempeng Total pada Teh Kering dalam Kemasan, Skripsi, Fakultas Farmasi, Program Studi Diploma III Analisis Farmasi dan Makanan, Universitas Sumatra Utara, Medan.

Sulistiyani \& Zulaikhah, ST, 2006, Beberapa Faktor yang Berhubungan dengan Kontaminasi Mikroorganisme pada Jamu Gendong di Kota Semarang, Biostera, vol. 23, no. 3, hal. 118-123.
Thayib, S \& Amar, A, 1989, Petunjuk Praktikum Mikrobiologi Pengolahan, Serpong: Laboratorium Mikrobiologi Pengolahan Fakultas Teknologi Pertanian, Institut Teknologi Indonesia.

Watung, TA, Jembel, DT \& Ijong, G.F, 2014, Komposisi Mikroorganisme pada Beberapa Depot Air Minum Isi Ulang di Kota Manado, Jurnal Ilmu dan Teknologi Pangan, vol. 2, no. 1, hal. 2-8.

Zdep M, Zamorska J \& Papicak D, 2016, Studying Microbiology of Rain Water for of Their Use in Economy, Journal of Ecological Engineering, vol. 17 , no. 3, hal. 203-208. 